\title{
Find Cancer Early: Evaluation of a Community Education Campaign to Increase Awareness of Cancer Signs and Symptoms in People in Regional Western Australians
}

\author{
Emma Jane Croager ${ }^{1}$, Victoria Gray ${ }^{2}$, lain Stephen Pratt ${ }^{1,3 *}$, Terry Slevin ${ }^{1,3}$, \\ Simone Pettigrew' ${ }^{3}$, C. D'arcy Holman ${ }^{2}$, Max Bulsara ${ }^{4}$ and Jon Emery ${ }^{5}$ \\ ${ }^{1}$ Cancer Council Western Australia, Subiaco, WA, Australia, ${ }^{2}$ University of Western Australia, Perth, WA, Australia, ${ }^{3}$ Western \\ Australian Cancer Prevention Research Unit, Curtin University, Perth, WA, Australia, ${ }^{4}$ University of Notre Dame Australia, \\ Fremantle, WA, Australia, ${ }^{5}$ University of Melbourne, Melbourne, VIC, Australia
}

\section{OPEN ACCESS}

Edited by:

Shane Andrew Thomas,

Shenzhen International Primary

Health Care Research Institute, China

Reviewed by:

Paul Russell Ward,

Flinders University, Australia

Bojana Matejic,

University of Belgrade, Serbia

${ }^{*}$ Correspondence:

lain Stephen Pratt

spratt@cancerwa.asn.au

Specialty section: This article was submitted to Public Health Education and Promotion, a section of the journal

Frontiers in Public Health

Received: 04 October 2017 Accepted: 22 January 2018 Published: 08 February 2018

Citation:

Croager EJ, Gray V, Pratt IS, Slevin T, Pettigrew S, Holman CD, Bulsara M and Emery J (2018) Find Cancer Early: Evaluation of a Community Education Campaign to Increase Awareness of Cancer Signs and Symptoms in People in Regional Western Australians.

Front. Public Health 6:22. doi: 10.3389/fpubh.2018.00022
Introduction: Cancer outcomes for people living in rural and remote areas are worse than for those living in urban areas. Although access to and quality of cancer treatment are important determinants of outcomes, delayed presentation has been observed in rural patients.

Methods: Formative research with people from rural Western Australia (WA) led to the Find Cancer Early campaign. Find Cancer Early was delivered in three regions of WA, with two other regions acting as controls. Staff delivered the campaign using a community engagement approach, including promotion in local media. Television communications were not used to minimize contamination in the control regions. The campaign evaluation was undertaken at 20 months via a computer-assisted telephone interview (CATI) survey comparing campaign and control regions. The primary outcome variable was knowledge of cancer signs and symptoms.

Results: Recognition and recall of Find Cancer Early and symptom knowledge were higher in the campaign regions. More than a quarter of those who were aware of the campaign reported seeing the GP as a result of their exposure.

Conclusion: Despite limited use of mass media, Find Cancer Early successfully improved knowledge of cancer symptoms and possibly led to changes in behavior. Social marketing campaigns using community development can raise awareness and knowledge of a health issue in the absence of television advertising.

Keywords: health promotion, early detection of cancer, community engagement, rural health, social marketing

\section{INTRODUCTION}

There is clear evidence worldwide that cancer outcomes for people living in rural and remote regions are poorer than those living in urban areas (1). Australia is no exception, and although over the past decade much progress has been made in decreasing cancer mortality overall, there has been little progress in decreasing cancer mortality in rural and remote parts of the country $(2,3)$. People living in these areas are $20-30 \%$ more likely to die within 5 years of a cancer diagnosis than people from metropolitan areas (4). 
Much of the research into why these disparities exist has focused on access to and quality of the treatment received by rural and remote patients $(2,5-7)$. As a result, policy initiatives have focused on reducing disparities in access to cancer treatment (8). Although treatment access is an important determinant of outcome, later presentation and later stage of diagnosis have also been observed in rural cancer patients $(9,10)$. International research indicates that the time taken to appraise symptoms and seek help (termed "patient delay") and symptom management in primary care are key determinants of cancer outcome (11). The longer it takes to diagnose cancer, the lower the survival rate for several common cancers $(12,13)$.

It has recently been shown in Western Australia (WA) that rural cancer patients are less aware of the common signs and symptoms of cancer and more likely to delay seeking medical help than their urban counterparts $(14,15)$. There are several reasons why these delays may occur, including poor awareness of symptoms, negative beliefs about cancer outcomes, barriers to symptomatic presentation, and poor awareness of cancer risk (16-21). Low awareness of cancer symptoms and barriers to help-seeking has been shown in the UK to be associated with longer delays in help-seeking (22). Furthermore, patients' cancer awareness and beliefs influence how promptly GPs refer them for further investigation and how promptly they receive effective treatment (22). Emery et al. have identified that core characteristics of rural Australians, such as optimism, stoicism, and machismo, probably also contribute to later presentation (15).

Social marketing involves using a range of marketing techniques and communication strategies to encourage changes in health behaviors primarily by influencing individuals' knowledge, attitudes, and behaviors $(23,24)$. Although a systematic review of cancer symptom awareness campaigns published in 2009 found insufficient evidence to support the effect of social marketing campaigns on presentation to health professionals (25). More recent studies have shown effects of exposure to campaigns on presentation and earlier cancer diagnoses (26-29). Reflecting these findings, community symptom awareness campaigns to reduce late presentation have formed a major component of the UK National Awareness and Early Diagnosis Initiative (NAEDI) to improve cancer outcomes (30).

\section{BACKGROUND AND RATIONALE}

In November 2011, Cancer Council WA launched a rural cancer symptom awareness campaign called "Find Cancer Early" in three rural regions of WA. The 2-year community-based social marketing campaign aimed to increase people's awareness of the common signs and symptoms of breast, bowel, lung, and prostate cancers, and encourage them not to make excuses to seek help from a doctor when experiencing these signs and symptoms. The target group was people aged 40 years and above. Each region had a local campaign officer responsible for (i) establishing stakeholder relationships with community organizations and local media and (ii) the delivery of campaign messages and activities. Over the 2 years, the main campaign dissemination strategies included modest and restricted paid advertising, unpaid publicity on local radio and in local newspapers and other regional publications, and extensive community engagement. This paper reports key findings from the process and impact evaluations of the first 20 months of the Find Cancer Early campaign.

\section{METHODS}

\section{Campaign Theory and Development The Find Cancer Early}

The Find Cancer Early public awareness campaign was delivered from November 2011 to 2013 in the Goldfields $\left(770,488 \mathrm{~km}^{2}\right)$, Wheatbelt $\left(155,256 \mathrm{~km}^{2}\right)$, and Great Southern $\left(39,007 \mathrm{~km}^{2}\right)$ regions of WA. Control regions were the Midwest $\left(470,000 \mathrm{~km}^{2}\right)$, and Southwest $\left(29,646 \mathrm{~km}^{2}\right)$ regions of WA (31). The Pilbara and Kimberley regions were excluded because they were demographically different to the control and campaign regions (higher proportion of younger and Aboriginal people and transient workforces) and had other structural barriers to the early detection and treatment of cancer (e.g., greater distances to primary care and treatment centers). The campaign and control regions were matched for population size, demographics, including age, sex, Aboriginality, and socioeconomic status (as determined by postcode) and cancer incidence.

\section{Find Cancer Early}

Find Cancer Early campaign materials were developed based on findings from a previous exploratory mixed-methods study that identified barriers to symptom appraisal and help-seeking behavior in people from rural WA (15). Key themes identified included optimism, stoicism, machismo, fear, embarrassment, and competing demands. Concepts reflecting these themes were developed using content from Cancer Research UK's "Spot Cancer Early" (now "Spot Cancer Sooner") and the UK National Health Service's " 3 week cough" campaigns $(32,33)$, incorporating language and imagery reflecting rural Western Australian values. Concepts were tested in community fora in the campaign target regions and feedback was used to further refine the campaign materials. The resulting materials were simple, non-medical, and used "everyday" words and imagery relevant to people in rural WA. As Cancer Council WA is a familiar brand in WA, the Find Cancer Early campaign materials used the same blue and yellow color scheme. The tagline "The earlier cancer is found, the greater chance of successful treatment" was included because participants in the exploratory study wanted the campaign to focus on the positives associated with early detection, rather than the negatives associated with cancer (15). The signs and symptoms communicated were agreed on and endorsed by cancer specialists as being important for the early detection of cancer.

The primary communication was a plain-language symptom checklist, which was used in print media, posters, and banners. Other materials included four 30s radio advertisements (one for each cancer type-breast, bowel, lung, and prostate), postcards featuring rural images and quotations about symptoms relevant to the four cancers, postcards providing strategies to overcome barriers to seeking help, and a DVD featuring health professionals and rural community members discussing the common signs and symptoms of the cancers and what to do. A campaign website was 
also developed (www.findcancerearly.com.au). Due to concerns over contamination into control regions, the website was not actively promoted or optimized for search engines.

Five campaign officers, with a combined full-time equivalent (FTE) of three full-time workers, delivered the campaign across the three campaign regions. These campaign officers all had training or experience in health promotion or community development. They used a community engagement approach to (i) build partnerships with community organizations and local media and (ii) disseminate the campaign messages across their regions through presentations, displays, and campaign resource distribution. Paid advertising (six bursts of 2-4 weeks) and unpaid publicity on local radio and in community newspapers and other regional publications supplemented this dissemination strategy. Television and online media were not used for either paid advertising or unpaid news stories to minimize contamination of the control regions.

\section{Process Evaluation}

Process measures included media exposure (paid and unpaid print and radio) and number of community presentations and displays delivered by campaign staff to promote the Find Cancer Early messages. Media exposure was estimated by the number and reach of paid and unpaid press and radio coverage. Newspapers and radio stations were carefully selected to minimize contamination of the control regions.

\section{Impact Evaluation}

The primary outcome variable was knowledge of cancer signs and symptoms. Other outcome variables included campaign awareness and monitoring and acting on signs and symptoms.

Computer-assisted telephone interviews (CATI) were conducted with adults 40 years of age and older from campaign $(n=726)$ and control $(n=726)$ regions. An a priori power analysis determined that this sample size would be sufficient to detect a $5 \%$ difference in impact measures between campaign and control regions (34). Households were randomly selected from the Western Australian White Pages telephone directory. Participants were excluded if they were under 40 , had not been resident in the region for at least 6 months, or were unable to complete the interview in English. The participation rate among those who were eligible was $94.1 \%$.

Quotas were set to ensure equal numbers of respondents from the campaign regions and control regions and equal representation by gender and age group (40-49, 50-64, and 65+ years). Interviews were carried out during a 4-week period from July 1, 2013. Ethics approval was obtained from The University of Western Australia's Human Research Ethics Committee (RA/4/1/ 4527).

To minimize order effects and priming, the questionnaire started with basic demographic information and cancer symptom knowledge before assessing campaign recall and recognition. The remainder of the questionnaire measured message salience, perceived impact, behavioral intention, and behavior change.

Symptom knowledge was assessed by one open-ended question asking respondents to nominate the most common signs and symptoms of cancer. Respondents were able to provide as many responses as desired. Responses were post-coded into categories by the interviewer.

Campaign awareness (recall plus recognition) was assessed using an existing campaign evaluation protocol (35-38). Specifically, campaign recall was evaluated by asking whether respondents had heard any health messages about cancer in the last year, and then probing for more information on those messages to identify mentions of the Find Cancer Early campaign. Campaign recognition among those exhibiting no recall was assessed by providing brief descriptions of the campaign materials and asking respondents whether they had seen them.

As per Morley et al. (37), four-point Likert-type scales (response anchors "strongly disagree" to "strongly agree") were used to assess whether the Find Cancer Early Campaign was perceived to be believable, easy to understand, personally relevant, informative, and a cause of discomfort among those respondents exhibiting campaign recall or recognition. Overall agreement or disagreement was calculated by summing "strongly agree" with "agree" and "strongly disagree" with "disagree." These respondents were also asked whether they had acted or considered acting on the campaign message and the nature of any such action.

\section{Statistical Analysis}

Data were analyzed using SPSS 24, with the null hypothesis having no difference between the campaign and control regions. Pearson chi-squared tests (two-sided) were conducted on all categorical data. Continuous data were analyzed using an independentsample's $t$-test.

\section{RESULTS}

\section{Sample Characteristics}

Sample characteristics are shown in Table 1. Quota sampling ensured that the campaign and control samples did not differ on key demographic characteristics (sex and age). There was no difference observed between the campaign and control samples in the proportion of respondents reporting a previous cancer diagnosis ( 15.4 vs $16.7 \%$, respectively, $p=0.52$ ).

\section{Process Evaluation}

After 20 months, 214,317 Find Cancer Early publications had been distributed, 435 community sessions were delivered, and

TABLE 1 | Campaign and control sample comparison.

\begin{tabular}{|c|c|c|c|c|c|c|}
\hline \multirow{2}{*}{\multicolumn{2}{|c|}{$\begin{array}{l}\text { Sample } \\
\text { characteristic }\end{array}$}} & \multicolumn{2}{|c|}{ Campaign } & \multicolumn{2}{|c|}{ Control } & \multirow[t]{2}{*}{ Campaign vs control } \\
\hline & & $n$ & $\%$ & $n$ & $\%$ & \\
\hline Sex & $\begin{array}{l}\text { Male } \\
\text { Female }\end{array}$ & $\begin{array}{l}356 \\
370\end{array}$ & $\begin{array}{l}49.0 \\
51.0\end{array}$ & $\begin{array}{l}354 \\
372\end{array}$ & $\begin{array}{l}48.7 \\
51.3\end{array}$ & $\begin{array}{c}\chi^{2}(1, N=1,452)=0.01 \\
p=0.92\end{array}$ \\
\hline Age & $\begin{array}{l}40-49 \\
50-64 \\
65+\end{array}$ & $\begin{array}{l}231 \\
248 \\
247\end{array}$ & $\begin{array}{l}31.8 \\
34.2 \\
34.0\end{array}$ & $\begin{array}{l}222 \\
252 \\
252\end{array}$ & $\begin{array}{l}30.6 \\
34.7 \\
34.7\end{array}$ & $\begin{array}{c}\chi^{2}(2, N=1,452)=0.26 \\
p=0.88\end{array}$ \\
\hline $\begin{array}{l}\text { History of } \\
\text { cancer }\end{array}$ & $\begin{array}{l}\text { Yes } \\
\text { No }\end{array}$ & $\begin{array}{l}121 \\
605\end{array}$ & $\begin{array}{l}16.7^{\circ} \\
83.3^{c}\end{array}$ & $\begin{array}{l}112 \\
614\end{array}$ & $\begin{array}{l}15.4 \\
84.6\end{array}$ & $\begin{array}{c}\chi^{2}(1, N=1,452)=0.414 \\
p=0.52\end{array}$ \\
\hline Total & & 726 & 100 & 726 & 100 & \\
\hline
\end{tabular}


691 unpaid media items had been achieved. This was in addition to paid advertising in local print and radio (Table 2).

\section{Campaign Impact on Knowledge}

During the telephone interview, knowledge of cancer signs and symptoms was assessed prior to campaign awareness to minimize priming. Participants were asked: "Can you please tell me what you think are the most common signs and symptoms of cancer?" This question was based on Cancer Research UK's Cancer Awareness Measure (CAM) for symptom awareness (39). The term "signs and symptoms" was explained if needed, but no further prompting occurred. The total number of cancer signs and symptoms correctly identified was higher in the campaign regions than in the control regions (1.65 vs 1.31 , $p=0.000)$. Notably, people in the campaign regions were more likely to identify "blood in your poo," "blood in your pee," and "an unusual pain, lump, or swelling" than people in the control regions (Table 3 ).

\section{Campaign Awareness}

Residents of the campaign regions were more likely than residents of the control region to have "heard or seen any health message about cancer in the last year," (88.2 vs $80.3 \%$; $\chi^{2}[1$,

TABLE 2 | Process measures November 2011-July 2013.

\begin{tabular}{lcc}
\hline Measure & Number & Estimated reach \\
\hline Checklists distributed & 130,388 & 130,388 \\
Postcards distributed & 78,317 & 78,317 \\
DVDs distributed & 4,170 & 4,170 \\
Aboriginal resources distributed & 1,262 & 1,262 \\
Community presentations & 312 & 6,549 \\
Static displays & 123 & 573,380 \\
Regional newspaper articles & 89 & 283,520 \\
Local newspaper/newsletter articles & 602 & $2,262,498$ \\
Radio interviews & 10 & \\
Paid newspaper advertisements (1/4 page) & 162 & 1,490 \\
Paid radio advertisements (30s) & \multicolumn{2}{c}{121,600} \\
\hline Total population aged 40 years and above & \multicolumn{2}{l}{} \\
\hline
\end{tabular}

TABLE 3 | Knowledge of cancer signs and symptoms.

\begin{tabular}{|c|c|c|c|c|c|c|}
\hline \multirow[t]{2}{*}{ Symptom recall } & \multicolumn{2}{|c|}{ Campaign } & \multicolumn{2}{|c|}{ Control } & \multicolumn{2}{|c|}{$\begin{array}{l}\text { Campaign vs } \\
\text { control }\end{array}$} \\
\hline & $n$ & $\%$ & $N$ & $\%$ & $\begin{array}{c}\chi^{2} \\
(1, N=1,452)\end{array}$ & $p$ \\
\hline $\begin{array}{l}\text { Coughing up blood } \\
\text { (included once) }\end{array}$ & 56 & 7.7 & 51 & 7.0 & 0.25 & 0.616 \\
\hline A cough or croaky voice & 53 & 7.3 & 38 & 5.2 & 2.64 & 0.104 \\
\hline $\begin{array}{l}\text { Becoming more short } \\
\text { of breath }\end{array}$ & 39 & 5.4 & 40 & 5.5 & 0.01 & 0.908 \\
\hline $\begin{array}{l}\text { Blood in your pee } \\
\text { (included once) }\end{array}$ & 128 & 17.6 & 60 & 8.3 & 28.25 & 0.000 \\
\hline Blood in your poo & 227 & 31.3 & 136 & 18.7 & 30.42 & 0.000 \\
\hline Problems peeing & 29 & 4.0 & 22 & 3.0 & 1.00 & 0.318 \\
\hline Looser poo (diarrhea) & 44 & 6.1 & 40 & 5.5 & 0.20 & 0.653 \\
\hline $\begin{array}{l}\text { An unusual pain, lump, } \\
\text { or swelling }\end{array}$ & 464 & 63.9 & 425 & 58.5 & 4.41 & 0.036 \\
\hline Unexplained weight loss & 157 & 21.6 & 140 & 19.3 & 2.80 & 0.094 \\
\hline
\end{tabular}

$N=1,452]=16.84, p=0.000)$. Residents of the campaign regions had greater recall and recognition of the Find Cancer Early campaign (Table 4). Total awareness (prompted and unprompted) was $61.4 \%$ in the campaign regions vs $20.4 \%$ in the control regions $\left(\chi^{2}[1, N=1,452]=253.00, p=0.000\right)$.

\section{Campaign Salience}

Most people who were aware of the campaign reported that it was easy to understand (98.5\%), believable (98.8\%), relevant to them (75.4\%), and did not make them feel uncomfortable (82.6\%). However, only $44 \%$ of people who were aware of the campaign felt that it taught them something new.

\section{Campaign Impact on Intention and Behavior}

Among those who were aware of the campaign, almost half (46.9\%) thought about doing something, and more than a third (34.3\%) reported doing something as a result of exposure. As shown in Table 5, the most common intention and behavior was to see a doctor/GP.

\section{DISCUSSION}

Awareness of the importance of the early detection of cancer, knowledge of cancer signs and symptoms, and self-reported cancer-related intentions or behaviors were higher in the Find Cancer Early campaign regions than in the control regions. Although the quasi-experimental, post-test design limits causal inference, the large effect sizes and lack of plausible confounders (resulting from demographically matched campaign and control regions and low likelihood of pre-existing differences in outcome measures) suggest that Find Cancer Early was a successful campaign. Outcomes were achieved despite the inability to use television and online media because of the need to avoid contamination in the control

TABLE 4 | Recall and recognition of the Find Cancer Early campaign.

\begin{tabular}{lrrrrr}
\hline Campaign awareness & \multicolumn{2}{c}{ Campaign } & & \multicolumn{2}{c}{ Control } \\
\cline { 2 - 3 } \cline { 5 - 6 } & $\boldsymbol{N}$ & $\%$ & & $\boldsymbol{n}$ & $\%$ \\
\hline Unprompted recall & 56 & 7.7 & 12 & 1.7 \\
Prompted recognition & 390 & 53.7 & & 136 & 18.7 \\
Not aware & 280 & 38.6 & & 578 & 79.6 \\
Total & 726 & 100 & & 726 & 100 \\
\hline
\end{tabular}

Campaign vs control: $\chi^{2}(2, N=1,452)=254.63, p=0.000$.

TABLE 5 | Intentions and behaviors among those aware of the Find Cancer Early campaign.

\section{Campaign impact} Aware of the campaign $(n=405)$

Intention (thought about...)

Seeing a doctor/GP

Monitoring symptoms

Increasing symptom knowledge

Behavior

Saw a doctor/GP

Monitored symptoms

$\begin{array}{rr}\boldsymbol{n} & \% \\ 117 & 28.9 \\ 43 & 10.6 \\ 15 & 3.7 \\ & \\ 105 & 25.9 \\ 22 & 5.4\end{array}$


regions. Importantly, the results suggest that it is possible to develop a successful social marketing campaign without these media forms when the target audience is rural communities and effort is invested in community development strategies. Further, the results support the potential effectiveness of the alternative social marketing activities used in the intervention, including community engagement by the regional campaign officers and delivery of the campaign through community partnerships and local paid media. A similar approach has previously been reported for successful delivery of the Act-Belong-Commit mental health campaign (40).

The encouraging outcome of the Find Cancer Early campaign in raising awareness is likely to be the result of two primary factors. First, extensive formative research was carried out with people living in regional WA to guide the development and refinement of campaign messages and materials (15). This resulted in the implementation of positively framed campaign messages using simple language and a clear call to action that was salient for the intended target audience. Second, the community engagement approach used alongside the limited purchased media was important in enhancing the reach of the campaign. Campaign officers successfully formed ongoing partnerships throughout their regions to promote campaign messages. Importantly, the media buy was supplemented substantially with unpaid media coverage that was generated by campaign officers developing effective working relationships with local community groups and media outlets. This was achieved by building personal relationships with local editorial staff and providing story and picture opportunities relevant to the communities targeted by these regional publications.

Due to the restriction on TV and online advertising, this study could not test the relative impact of mass media advertising in communicating early detection messages compared to the community-based approach adopted in the Find Cancer Early campaign. It is likely that greater investment in the intervention and the use of high impact media channels such as television would have achieved better outcomes. Future campaign evaluation will potentially allow for these comparisons to be made.

Symptom awareness campaigns remain a major strategy internationally as part of cancer control. For example, they have formed a major component of the UK NAEDI to improve cancer outcomes (30). Initial observational data from a lung cancer awareness campaign in England showed greater intentions to attend a GP with a cough, increases in chest X-ray requests, and higher incidence of lung cancer diagnoses (26).

\section{REFERENCES}

1. Coleman MP, Forman D, Bryant H, Butler J, Rachet B, Maringe C, et al. Cancer survival in Australia, Canada, Denmark, Norway, Sweden, and the UK, 1995-2007 (the International Cancer Benchmarking Partnership): an analysis of population-based cancer registry data. Lancet (2011) 377(9760):127-38. doi:10.1016/S0140-6736(10)62231-3

2. Coory MD, Ho T, Jordan SJ. Australia is continuing to make progress against cancer, but the regional and remote disadvantage remains. Med J Aust (2013) 199(9):605-8. doi:10.5694/mja13.10055

3. Australian Institute of Health and Welfare (AIHW), Australasian Association of Cancer Registries (AACR). Cancer in Australia: An Overview 2014. Canberra: AIHW (2014). (Cancer series No. 90. Cat. no. CAN 88).
This evaluation has limitations. Most notable, as previously mentioned, the cross-sectional, single-time-point data collection does not allow for causation to be inferred. In addition, individual-level socioeconomic data were not collect, so it is not possible to say that the control and campaign samples were matched or representative for education or income.

There are lessons for practice that can be taken from this evaluation. First, the importance of formative research in the development of the campaign materials. It is likely that the strong campaign awareness was in part due to the salience of the materials. Second, community engagement-or on the ground health promotion-remains an effective yet often overlooked strategy in changing knowledge, attitude, and beliefs, at least in older adults living in regional communities. Finally, it is important to evaluate behavior change campaigns, particularly when delivered via nontraditional methods.

\section{CONCLUSION}

Evaluation of Find Cancer Early demonstrates the potential effectiveness in rural communities of a modest social marketing campaign combined with community development strategies in increasing awareness of cancer signs and symptoms.

\section{AUTHOR CONTRIBUTIONS}

TS, JE, CH, VG, and EC conceptualized and designed the study. EC managed campaign and staff. VG developed and tested materials, and coordinated campaign delivery. IP developed and tested evaluation survey and analyzed data. MB provided statistical expertise to ensure sample size powered adequately. SP contributed to evaluation survey design and analysis. JE and $\mathrm{CH}$ conceptualized and designed the Improving Rural Cancer Outcomes (IRCO) study. All authors have been involved in drafting and critical evaluation of the manuscript.

\section{FUNDING}

Find Cancer Early was part of the IRCO project. IRCO was funded by a National Health Medical Research Council (NHMRC) Partnership Grant (Grant ID 572765) and the AH Crawford Society. Find Cancer Early message development and testing was funded by a Cancer and Palliative Care Research and Evaluation Unit (CaPCREU) Small Grant. Campaign evaluation was funded by the Val Lishman Health Research Foundation.

4. Australian Institute of Health and Welfare (AIHW). Rural, Regional and Remote Health: Indicators of Health System Performance. Canberra: AIHW (2008). (Rural Health Series No. 10. Cat. No. PHE 103).

5. Baade PD, Dasgupta P, Aitken JF, Turrell G. Distance to the closest radiotherapy facility and survival after a diagnosis of rectal cancer in Queensland. Med J Aust (2011) 195(6):350-4. doi:10.5694/mja10.11204

6. Hall SE, Holman CD, Wisniewski ZS, Semmens J. Prostate cancer: socio-economic, geographical and private-health insurance effects on care and survival. BJU Int (2005) 95(1):51-8. doi:10.1111/j.1464-410X.2005.05248.x

7. Mitchell KJ, Fritschi L, Reid A, McEvoy SP, Ingram DM, Jamrozik K, et al. Rural-urban differences in the presentation, management and survival of breast cancer in Western Australia. Breast (2006) 15(6):769-76. doi:10.1016/j. breast.2006.04.001 
8. Department of Health and Ageing. Delivering Better Cancer Care. Canberra (2010). Available from: http://www.health.gov.au/internet/publications/publishing.nsf/Content/cancer-policy-booklet $\sim$ What+the+Government+is+doing+to+tackle+cancer

9. Baade PD, Dasgupta P, Aitken J, Turrell G. Geographic remoteness and risk of advanced colorectal cancer at diagnosis in Queensland: a multilevel study. $\mathrm{Br}$ J Cancer (2011) 105(7):1039-41. doi:10.1038/bjc.2011.356

10. Jong KE, Vale PJ, Armstrong BK. Rural inequalities in cancer care and outcome. Med J Aust (2005) 182(1):13-4.

11. Allgar VL, Neal RD. Delays in the diagnosis of six cancers: analysis of data from the National Survey of NHS patients: cancer. Br J Cancer (2005) 92(11):1959-70. doi:10.1038/sj.bjc.6602587

12. Richards MA, Smith P, Ramirez AJ, Fentiman IS, Rubens RD. The influence on survival of delay in the presentation and treatment of symptomatic breast cancer. Br J Cancer (1999) 79(5-6):858-64. doi:10.1038/sj.bjc.6690137

13. Torring ML, Frydenberg M, Hansen RP, Olesen F, Hamilton W, Vedsted P. Time to diagnosis and mortality in colorectal cancer: a cohort study in primary care. Br J Cancer (2011) 104(6):934-40. doi:10.1038/bjc.2011.60

14. Emery JD, Walter FM, Gray V, Sinclair C, Howting D, Bulsara M, et al. Diagnosing cancer in the bush: a mixed methods study of GP and specialist diagnostic intervals in rural Western Australia. Fam Pract (2013) 30(5):541-50. doi:10.1093/fampra/cmt016

15. Emery JD, Walter FM, Gray V, Sinclair C, Howting D, Bulsara M, et al. Diagnosing cancer in the bush: a mixed-methods study of symptom appraisal and help-seeking behaviour in people with cancer from rural Western Australia. Fam Pract (2013) 30(3):294-301. doi:10.1093/fampra/cms087

16. Forbes LJ, Linsell L, Atkins L, Burgess C, Tucker L, Omar L, et al. A promoting early presentation intervention increases breast cancer awareness in older women after 2 years: a randomised controlled trial. Br J Cancer (2011) 105(1):18-21. doi:10.1038/bjc.2011.205

17. Grunfeld EA, Ramirez AJ, Hunter MS, Richards MA. Women's knowledge and beliefs regarding breast cancer. Br J Cancer (2002) 86(9):1373-8. doi:10.1038/ sj.bjc. 6600260

18. Macleod U, Mitchell ED, Burgess C, Macdonald S, Ramirez AJ. Risk factors for delayed presentation and referral of symptomatic cancer: evidence for common cancers. Br J Cancer (2009) 101(Suppl):S92-101. doi:10.1038/sj.bjc. 6605398

19. Robb K, Stubbings S, Ramirez A, Macleod U, Austoker J, Waller J, et al. Public awareness of cancer in Britain: a population-based survey of adults. $\mathrm{Br}$ J Cancer (2009) 101(Suppl 2):s18-23. doi:10.1038/sj.bjc.6605386

20. Ramirez AJ, Westcombe AM, Burgess CC, Sutton S, Littlejohns P, Richards MA. Factors predicting delayed presentation of symptomatic breast cancer: a systematic review. Lancet (1999) 353(9159):1127-31. doi:10.1016/S01406736(99)02142-X

21. von Wagner C, Good A, Whitaker KL, Wardle J. Psychosocial determinants of socioeconomic inequalities in cancer screening participation: a conceptual framework. Epidemiol Rev (2011) 33(1):135-47. doi:10.1093/epirev/mxq018

22. Mitchell E, Macdonald S, Campbell NC, Weller D, Macleod U. Influences on pre-hospital delay in the diagnosis of colorectal cancer: a systematic review. Br J Cancer (2008) 98(1):60-70. doi:10.1038/sj.bjc.6604096

23. Hastings G, McDermott L. Putting social marketing into practice. BMJ (2006) 332(7551):1210-2. doi:10.1136/bmj.332.7551.1210

24. Wakefield MA, Loken B, Hornik RC. Use of mass media campaigns to change health behaviour. Lancet (2010) 376(9748):1261-71. doi:10.1016/ S0140-6736(10)60809-4

25. Austoker J, Bankhead C, Forbes LJL, Atkins L, Martin F, Robb K, et al. Interventions to promote cancer awareness and early presentation: systematic review. Br J Cancer (2010) 101(S2):S31-9. doi:10.1038/sj.bjc.6605388

26. Athey VL, Suckling RJ, Tod AM, Walters SJ, Rogers TK. Early diagnosis of lung cancer: evaluation of a community-based social marketing intervention. Thorax (2012) 67(5):412-7. doi:10.1136/thoraxjnl-2011-200714
27. Eadie D, MacKintosh AM, MacAskill S, Brown A. Development and evaluation of an early detection intervention for mouth cancer using a mass media approach. Br J Cancer (2009) 101(Suppl):s73-9. doi:10.1038/sj.bjc. 6605395

28. Jedele JM, Ismail AI. Evaluation of a multifaceted social marketing campaign to increase awareness of and screening for oral cancer in African Americans. Community Dent Oral Epidemiol (2010) 38(4):371-82. doi:10.1111/j.16000528.2010.00545.x

29. Peacock O, Clayton S, Atkinson F, Tierney GM, Lund JN. "Be Clear on Cancer": the impact of the UK National Bowel Cancer Awareness Campaign. Colorectal Dis (2013) 15(8):963-7. doi:10.1111/codi.12220

30. Cancer Research UK. National Awareness and Early Diagnosis Initiative (NAEDI). (2010). Available from: http://www.cancerresearchuk.org/cancer-info/ spotcancerearly/naedi/AboutNAEDI/

31. Emery JD, Gray V, Walter FM, Cheetham S, Croager EJ, Slevin T, et al. The Improving Rural Cancer Outcomes (IRCO) Trial: a factorial cluster-randomised controlled trial of a complex intervention to reduce time to diagnosis in rural patients with cancer in Western Australia: a study protocol. BMJ Open (2014) 4:e006156. doi:10.1136/bmjopen-2014-006156

32. Cancer Research UK. Spot Cancer Sooner. (2016). Available from: http://www. cancerresearchuk.org/about-cancer/cancer-symptoms/spot-cancer-sooner

33. National Health Service. 3 Week Cough. (2016). Available from: http://www. nhs.uk/be-clear-on-cancer/lung-cancer/home

34. Dupont WD, Plummer WD. Power and sample size calculations for studies involving linear regression. Control Clin Trials (1998) 19:589-601. doi:10.1016/ S0197-2456(98)00037-3

35. Hollier LP, Pettigrew S, Slevin T, Strickland M, Minto C. Comparing online and telephone survey results in the context of a skin cancer prevention campaign evaluation. J Public Health (Oxf) (2017) 39(1):193-201. doi:10.1093/ pubmed/fdw018

36. Niederdeppe J. Assessing the validity of confirmed ad recall measures for public health communication campaign evaluation. J Health Commun (2005) 10(7):1081-730. doi:10.1080/10810730500267662

37. Morley B, Niven P, Dixon H, Swanson M, Szybiak M, Shilton T, et al. Population-based evaluation of the "LiveLighter" healthy weight and lifestyle mass media campaign. Health Educ Res (2016) 31(2):121-35. doi:10.1093/her/ cyw009

38. Dixon HG, Pratt IS, Scully ML, Miller JR, Patterson C, Hood R, et al. Using a mass media campaign to raise women's awareness of the link between alcohol and cancer: cross-sectional pre-intervention and post-intervention evaluation surveys. BMJ Open (2015) 5:e006511. doi:10.1136/bmjopen-2014006511

39. Cancer Research UK. The Cancer Awareness Measures (CAM). (2016). Available from: http://www.cancerresearchuk.org/health-professional/prevention-andawareness/the-cancer-awareness-measures-cam

40. Anwar-McHenry J, Donovan RJ, Jalleh G, Laws A. Impact evaluation of the Act-Belong-Commit mental health promotion campaign. J Public Ment Health (2012) 11(4):186-94. doi:10.1108/17465721211289365

Conflict of Interest Statement: The authors declare that the research was conducted in the absence of any commercial or financial relationships that could be construed as a potential conflict of interest.

Copyright (c) 2018 Croager, Gray, Pratt, Slevin, Pettigrew, Holman, Bulsara and Emery. This is an open-access article distributed under the terms of the Creative Commons Attribution License (CC BY). The use, distribution or reproduction in other forums is permitted, provided the original author(s) and the copyright owner are credited and that the original publication in this journal is cited, in accordance with accepted academic practice. No use, distribution or reproduction is permitted which does not comply with these terms. 